\title{
Combinations of Injunctions and Personality Types Determining Forms of Self-Destructive Behaviour in Alcohol-Dependent Clients: Findings of a Russian Observational Study
}

\author{
(C) 2016 Dmitri I. Shustov, Olga D. Tuchina, Sergei A. Novikov \&
} Ilya A. Fedotov

\begin{abstract}
This observational study, conducted 2009-2012 with 190 male out-patient clients diagnosed with alcohol dependence and receiving psychotherapeutic treatment in Ryazan, Russia, investigated whether the patterns of self-destructive behaviours exhibited by the subjects were linked to their Personality Types and which combinations of injunctions were reflected in their main personality traits.
\end{abstract}

Self-destructive behaviour was measured according to the 7 Alcoholic Self-Destructiveness Dimensions (ASD) (Shustov 2005); data on alcohol abuse and preferred ASD were gathered through semi-structured interview; personality patterns and psychosocial functioning were assessed by means of clinical observation, semistructured interview, the Personality Diagnostic Questionnaire: Version 4+ (Hyler, 1994) (Russian version) and $I C D-10$ criteria except for Narcissistic Disorder diagnosed according to DSM-IV; 12 injunctions were assessed with The Drego Injunction Scale (Drego, 1994) (Russian version).

When correlations were analysed, it was found that injunctions had a significant impact on the hamartic alcoholic script of the out-patient alcohol-dependent clients on the following continuum: Don't Be, Don't Think, Don't Be a Child, Don't Trust, Don't Feel, Don't Grow Up; client personality types had direct relationship with specific injunction patterns. Personality Types mediated the Alcoholic Self-Destructiveness Dimensions: the Classical Suicidal Dimension being associated with Borderline personality traits; Antisocial with the Antisocial personality; and Professional with the Narcissistic Personality.

\section{Key words}

psychotherapy, substance use disorders, alcohol dependence, suicide, injunctions, personality disorders, adaptations, transactional analysis, self-destructive behaviour, Russia.

\section{Background}

Today, psychotherapy for alcohol dependence and alcohol use disorders in general includes many evidence-based approaches and methods (e.g. NIDA National Institute of Drug Abuse, 2012). Most of these evidence-based psychotherapies are cognitive behavioural (CBT) methods focusing on distress or relapse prevention, recognition and management of alcoholic triggers as well as coping with negative emotions and cravings (Magill \& Ray, 2009). Personalityoriented methods involve reparative work on dissociation and early traumas suffered in dysfunctional families or as a result of different kinds of abandonment (Najavits, 2013). There are also combined approaches such as disulfiram (antabuse) contracts in behavioural couple's therapy for alcoholism (O'Farrell \& Clements, 2012), behavioural self-control training or other CBT interventions combined with naltrexone, nalmephene or other medications (Niciu \& Arias, 2013). In TA terms, most of these evidence-based methods focus on decontamination, strengthening the resources of the Adult ego state, On the other hand, therapists and clients are less aware of transference which develops within a lasting therapeutic relationship and makes it possible for the therapist's figure to be introjected into the client's Parent (P2) along with new permissions (Crossman, 1966). Unfortunately, official medicine and the Alcoholics Anonymous community consider cases of alcoholic script redecision and cure achieved by clients to be casuistry. 
At the same time, current epidemiological research suggests that there are multiple outcomes of alcohol dependence or harmful alcohol use among clients. Few people with clinical symptoms of alcohol dependence apply for Substance Use Disorders treatment (SUD treatment) (NIAAA - National Institute on Alcohol Abuse and Alcoholism, 2006). About two thirds of them cure alcohol dependence (through controlled drinking or complete abstaining) naturally, without any professional help (Cunningham, Breslin \& Curtis, 2004). An opinion that alcohol dependence is, first and foremost, a chronic disease with poor treatment outcome, has been based mainly on the findings of observation of 'difficult' patients seeking treatment and usually having comorbid disorders, whereas the situation at the population level is completely different (Cunningham \& McCambridge, 2012).

Berne (1981) challenged the medical paradigm of alcohol dependence as early as the middle of the 20th century. $\mathrm{He}$ argued that this pessimistic model justified doing nothing during the treatment of that 'incurable disease' and suggested giving up all 'labels and diagnoses' and analysing a game of 'Alcoholic'. "In game analysis there is no such thing as "alcoholism" or an "alcoholic", but there is a role called the Alcoholic in a certain type of game" (p.30).

Elaborating on Berne's ideas, Steiner (1974) described an 'alcoholic' life script as a curable alternative to alcohol dependence: "Like diseases, scripts have an onset, a course, and an outcome. Because of this similarity, scripts have been mistaken for diseases. However, because scripts are based on consciously willed decisions rather than on morbid tissue changes, they can be revoked or "undecided" by similarly willed decisions. Thus, I believe that a cured alcoholic (though he often does not choose to) will be able to return to social drinking, while the person who returns to uncontrollable drinking after one drink has been essentially unable to dispose of his script" (p.17).

Steiner believed that the main 'alcoholic' injunction was 'Don't Think' actualising in frustrating situations, triggering drinking and, therefore, preventing people from solving issues in the here-and-now, i.e. decathecting the Adult ego state. Furthermore, Steiner mentioned the role of the 'Don't Be' injunction in people with so-called hamartic life scripts, emphasising their inclinations to different self-destructive behaviours. It is interesting that at the beginning of the 20th century, an observation that alcohol-dependent people were at high risk of suicide or other self-destructive behaviours enabled Menninger (1993) to call this condition a form of 'chronic suicide'.

Comparing data received in a therapeutic situation in a group of alcohol-dependent clients $(n=135)$ and a group of non-alcohol-dependent controls $(n=49)$, we found that $45 \%$ of alcohol-dependent clients had the 'Don't Be' injunction versus $21.7 \%$ of the controls (intergroup differences were significant at $p=0.02$ ) (Shustov, 2000). The 'Don't Be' incidence increased on the following continuum (at the statistical significance level of $p<0.05$ ):
- clients without suicidal ideation (34\%);

- $\quad$ clients with suicidal ideation (38.8\%);

- clients with suicidal attempts (95.6\%).

Elaborating on our research, we used exploratory factor analysis to single out historical, psychological and clinical variables that were associated with classical suicidal behaviour in alcohol-dependent patients. Variables with highest factor weights represented a wide range of phenomena (e.g. multiple bone fractures, birth defects, inferiority complex, etc.), and thus we hypothesised that self-destructive activity in alcoholics might be multidimensional. That is, it would not limit itself to conscious somatic self-destruction through suicides and suicidal attempts alone, but might actualise through professional failures or family system collapses. Using clinical analysis and semantic matching, we grouped these relevant factors according to seven dimensions: Classical Suicidal Self-Destructiveness; Family SelfDestructiveness; Somatic Self-Destructiveness; Risky Behaviour; Antisocial Behaviour; Professional SelfDestructiveness; Dual Diagnosis. We also thoroughly studied additional characteristics of clients demonstrating self-destructive behaviours within the above dimensions (Shustov, 2005, 2009; Merinov \& Shustov, 2012; Shustov, Merinov \& Tuchina, 2015). Grouping and additional factor characteristics of the Alcoholic SelfDestructiveness Dimensions (ASD) are provided below.

At the same time, the described variability of the behavioural forms of Alcoholic Self-Destructiveness was to be explored at the intrapsychic level. We assumed that the choice of the ASD depended on a combination of different injunctions, with 'Don't Be' reflecting the main pattern of the client's personality traits, i.e. the Personality Type. This hypothesis was based on two premises. Firstly, alcoholics who commit fatal suicide generally have no serious alcohol-related somatic medical conditions whereas high density of alcohol-related illnesses in the general population of alcohol-dependent patients is a well-known fact. Research shows that medical illnesses reinforce suicidal ideation and planning, but they are not related to an increase in the number of suicidal attempts (Pompilli et al, 2010). Our own post-mortem study of suicidal patients with alcohol dependence revealed few patients with severe somatic conditions and burn injuries (Shustov, 2000), although up to $40-50 \%$ patients of burns units are people with alcohol use disorders (Davis \& Loxton, 2013; Egorov, Krupitsky, Sofronov, Bobrov, Tyavokina \& Dobrovolskaya, 2013). In other words, it can be assumed that the choice of the way of death is scripty: those who decide to die from alcoholrelated destruction of the viscera do not commit suicide.

Secondly, it is known that specific features of selfdestructive behaviour are related to specific personality types, e.g. borderline, antisocial, narcissistic personalities etc. (Chachamovich, Ding \& Turecki, 2012; Larkin, Di Blasi \& Arensman, 2014; Wedig, Silverman, Frankenburg et al, 2012). Therefore, different ASDs might depend on the structure of clients' personality. 
There are multiple definitions of personality and personality types and multiple approaches to their classification, usually accounting for the continuum existing between the 'norm' (commonly described as styles, adaptations and types) and the 'pathology' (disorders, psychopathy, etc). In TA, personality types are generally described in terms of the Personality Adaptations concept (Ware, 1983; Joines, 1986, 1988; Hoyt, 1989; Joines \& Stewart, 2002). In the Russian academic tradition, this concept is very close to the term "personality accentuation" introduced by Leonhard (1968) and specified by Russian psychiatry researchers as denoting an extreme variant of normal psychological functioning, when separate personality traits get so intense that the person becomes vulnerable to specific psychological and social triggers, whilst at the same time remaining continually, and sometimes highly, resilient to all the other triggers (Lichko, 1983). Therefore, the TA concept of personality adaptations is consistent with the traditions of the Russian medical research and was employed as a qualitative measure of personality by some Russian researchers (Agibalova, Buzik \& Gurevich, 2011; Novikov, 2014). Thus, for the purposes of our study, the Personality Type was defined as a pattern of stable personality traits that would determine the individual's psychosocial functioning and would lie on a 'norm-pathology' continuum ranging from Personality Adaptation Trends through Personality Adaptation to Personality Disorders (see Methods for research definitions).

\section{Research Question and Objectives}

Taking into account this background, the research question of the current study was how a combination of the Don't $\mathrm{Be}$ with other injunctions would change depending on alcohol-dependent clients' Personality Types. To answer the question, the following study objectives were generated:

1. To identify the range of injunctions found in alcohol-dependent clients;

2. To assess the relationship between these injunctions and clients' Personality Types;

3. To assess the relationship between Personality Types and Alcoholic Self-Destructiveness Dimensions.

\section{Funding and Ethical Considerations}

The study was approved by the Ethics Committee of the Ryazan State Medical University. All clients agreed to participate in the study on a voluntary basis and signed Informed Consents for participation. The confidentiality principle was observed. Clients had the right to withdraw from the study at any stage. Ethical issues were controlled for through the use of contracts that provided for the terms, timing, and responsibilities of the parties during the study and the treatment involved. If necessary (history of suicidal attempts, suicidal ideation and suicidal trends, self-injuries, history of suicides in close relatives, etc), no-suicide or noharm contracts were made.

\section{Methodology}

The material presented in this article (Study B) is part of a larger study (Study A) aimed at developing guidelines for the psychotherapeutic treatment accounting for Alcoholic Self-Destructive and Personality Types in alcohol-dependent men (Figure 1). The objectives of both Study $A$ and Study B were achieved through using observational research design (cohort study). Study A investigated relationships between Alcoholic SelfDestructiveness and Personality Types in three cohorts of clients: clients with Personality Adaptation Trends; clients with Developed Personality Adaptations; clients with Personality Disorders. It also evaluated the therapeutic outcome of a brief psychotherapeutic anti-alcohol intervention equivalent in the three groups and aimed at reduction of cravings for alcohol.

\section{The sample}

The studied sample consisted of 190 male clients, mean age $37(9.4 ; 21 \div 64)$. The inclusion criteria were male sex; the diagnosis of alcohol dependence based on ICD-10 criteria (F10.2) (World Health Organisation, 1992); informed consent to participate. The clients displaying signs of organic CNS disorder, acute psychosis, severe somatic conditions and women were excluded from the study. We excluded women to achieve homogeneity of the sample as there are clear gender differences in manifestations of self-destructiveness, such as findings that indicate the suicide risk in men is ten times that of women (Kocić, Radovanović S, Vasiljević et al, 2012).

All clients in the sample $(\mathrm{N}=190)$ participated in a psychotherapeutic interview. 46 people (24.2\%) dropped out of the study after Stage 1 and refused from the therapy. The drop-out after Stages 1 and 2 was not significant for Study B, as it was based on the whole sample's data, and data remained valid as all clients had given informed consent to the study and the use of their data after possible withdrawal.

\section{Procedure}

Study B drew on the data of the heterogeneous cohort of all Study A clients, which is therefore described here. We performed Study A in 2009-2012 among 190 male clients who applied for anonymous out-patient brief psychotherapy for alcohol dependence in Ryazan, an industrial and academic city in the central part of Russia, with 600000 citizens. To minimize the impact of affective disorders typical of the acute alcohol withdrawal stage, clients were examined from days 7 to 14 of abstinence.

Study A schedule for every client followed the logic of the psychotherapeutic process: Administrative Contracting and Psychotherapeutic Interview (Stage 1st Session); Therapeutic Contracting (Stage 2); Brief Intervention (Stage 3); Follow-up and Supportive Psychotherapy (Stage 4) (Figure 1). 


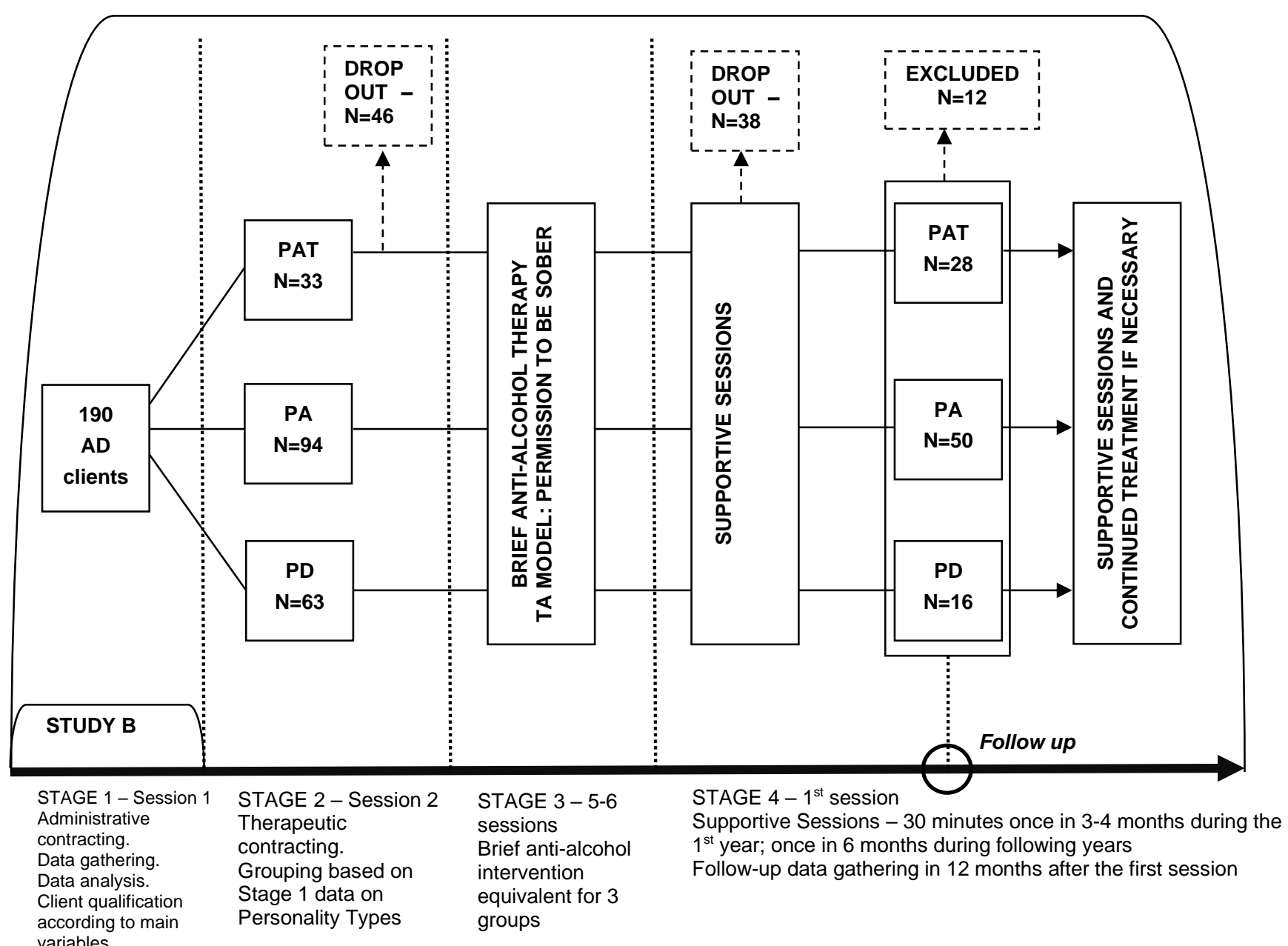

variables.

correlations.

Please, note:

Drop-out - Number of clients who withdrew from treatment

Excluded - clients excluded from analysis because they needed medication treatment at some stage of the study

AD - alcohol-dependent; PAT - Personality Adaptation Trends; PA - Personality Adaptation; PD - Personality Disorder

\section{Figure 1. Study design and scheduling}

During Stage 1, a psychotherapist, who was responsible for the client's therapy later, conducted a therapeutic interview with the client, gathering information on his social and demographic characteristics, history of alcohol abuse, self-destructive behaviour, personality type and negative parental messages received in childhood.

Study B drew on Study A but for Stage 1 had several research sub-stages:

- data gathering;

- $\quad$ statistical processing of the data: descriptive statistics, analysing correlations;

- data interpretation.

Therapy sessions at Stages 2 and 3 lasted from 45 minutes (usually) to 90 minutes if there was a need to work through intensive emotions such as fear of death, anger, guilt and shame (Type 2 decontamination - Adult-Child
Decontamination). If necessary, a therapist used parenting to provide for Type 1 decontamination (McNeel, 1976; Osnes, 1974). No-suicide/homicide/etc contracting usually concluded brief decontamination work. Brief therapy for alcohol dependence accounted for the effect of expectations (placebo effect) which is one of the main non-specific (common) active ingredients of psychotherapy (Constantino, Ametrano \& Greenberg, 2012). Utilization of the placebo effect in therapy is based on clients' experiences and expectations that widespread medical procedures, i.e. such as treatment with medication or special devices, would be efficient and would help them (Benedetti, 2013). In our case, during the last session of Stage 3, clients received one session of Transcranial Magnetic Stimulation (TMS) suggested for the treatment of alcohol dependence (Mishra, Nizamie, Das \& Praharaj, 2010). TMS was accompanied with a verbal statement of the danger of using alcohol after the 
TMS session (it is important to note that preliminary nosuicide contracting was a prerequisite for this work in order to prevent 'suicidal' intentional manipulative drinking). The overarching goal of this approach was to give a new therapeutic permission (through introjections of the therapist's image into the client's P2) shaped as the following statement (or a command!), "You can live a sober life".

Generally, Stage 3 - the active stage of therapeutic interventions - lasted no longer than 30 days (1-2 sessions a week), followed with supportive 30-minute interventions once in 3 or 4 months during 12 months, and once in 6 months throughout the following years of therapeutic remission from alcohol dependence. The follow-up data gathering for every client was performed 12 months after the study onset .

Variables and measures

The main Study B variables were qualitative, categorical, dichotomous data. The general principle of qualifying the variables (described below) was that the researchers took into account the whole set of the data gathered, including those obtained via psychodiagnostic testing, semi-structured interview, clinical observation, history analysis, medical documentation provided by the clients, and conversations with relatives (with client agreement).

Psychodiagnostic testing included three measures: a validated Russian version of the Personality Diagnostic Questionnaire - Version 4+ (Hyler, 1994); the Questionnaire of Present and Past Suicidal and Non-Suicidal Behavioural Manifestations (Shustov, Merinov \& Valentik, 2000), and the Drego Injunction Scale (Drego, 1994). The applied version of PDQ-4 was translated into Russian and validated by Dvorshchenko (2008) and has been used in personality disorders research in Russia. The Questionnaire of Present and Past Suicidal and Non-Suicidal SelfDestructive Behavioural Manifestations was developed by one of the authors (Shustov) and validated in terms of a study of alcoholic self-destructiveness in a sample of patients with alcohol dependence. It was approved by the Russian Ministry of Health for diagnosis of self-destructive behaviour. The Russian version of the Drego Injunction Scale was not subject to a special validation procedure save for evaluation of the equivalence of translation from English into Russian by a linguist and a psychologist with TA knowledge. The Drego Scale was used mostly for informative purposes to help the investigators make a more accurate diagnosis of the subjects' parental injunctions.

Self-destructive behaviour was measured according to the 7 Alcoholic Self-Destructiveness Dimensions (Shustov, 2005):

1. Classical Suicidal Self-Destructiveness displaying as self-injury (clients with a history of suicides, suicidal attempts, suicidal ideation and tendencies).

2. Family Self-Destructiveness: the factor of divorce and being divorced at the time of examination, subjective evaluation of the marriage as an unhappy one, childlessness, feelings of isolation and hopelessness.
3. Somatic Self-Destructiveness: presence of a moderately severe chronic somatic condition or multiple conditions, consequences of domestic burns, multiple surgeries, amputations, experiencing somatic and mental inferiority complex.

4. Risky Behaviour: multiple bone fractures (more than two), history of head injury with loss of consciousness, accidents, conscious inclination to risk, use of alcohol surrogates and alcohol poisoning with hospitalising into Emergency Unit.

5. Antisocial Behaviour: episodic use of illegal drugs, provocation of physical violence (including provoking police officers), history of conviction, conscious ability to violate social moral standards, proneness to stealing, being aggressive both when sober and under alcohol intoxication.

6. Professional Self-Destructiveness: loss of job within the last year and unemployed as at the date of examination, belief in immortality of the products of their work.

7. Dual Diagnosis Group: visiting a psychiatrist to treat mental disorder (save for alcohol dependence), diagnosis of a comorbid mental disorder, Post-Traumatic Stress Disorder, head injury consequences, depressive episodes, episodic use of illegal drugs, history of alcoholrelated psychosis, withdrawal-related paroxysmal disorders.

The data on alcohol abuse and preferred ASD were gathered through semi-structured interview based on the Questionnaire of Present and Past Suicidal and NonSuicidal Self-Destructive Behavioural Manifestations (Shustov, Merinov \& Valentik, 2000). The Questionnaire consists of 3 sections: General Information, Substance Use and Alcoholic Self-Destructiveness Dimensions. The client and the practitioner filled out the Questionnaire during the non-directive interview demonstrating protective and reparative aspects of the therapeutic process. The researchers assessed the interview data from the clinical perspective and identified ASDs the client preferred taking into account objective and subjective information.

Personality type: variables to describe Personality Types reflected the norm-pathology continuum Personality Adaptation Trends (Normal Functioning) - Personality Adaptations - Personality Disorders. Thus, we assumed that there might be at least three categories of people on the norm-pathology continuum:

- $\quad$ Clients with Personality Adaptation Trends - whose functioning can be described as 'normal' but having traits of Personality Adaptations actualized in certain, usually emotionally intensive, situations;

- Clients with Personality Adaptation - individuals with expressed traits of Personality Adaptations visible in their daily functioning;

- $\quad$ Clients with Personality Disorders. 
For the purposes of the study, we adopted Tilney's (1998) definition of Personality Adaptation as "a structuring of the personality that is compatible with normal functioning but shows similarities to certain types of psychological disorder" (p.88).

Personality Disorder was defined as "an enduring pattern of inner experience and behaviour that deviates markedly from the expectations of the individual's culture, is pervasive and inflexible, has an onset in adolescence or early adulthood, is stable over time, and leads to distress or impairment" (American Psychiatric Association, 1994, p.629).

The following Personality Types were measured: Paranoid, Schizoid, Dissocial (Antisocial), Emotionally Unstable (Borderline), Histrionic, Anankastic (ObsessiveCompulsive), Anxious (Avoidant), Dependent, Narcissistic, and Passive-Aggressive.

The method of semi-structured interview allowed the collection of information on the clients' personality patterns and specific features of their psychosocial functioning. As an objective measure to assess the personality type, we used a validated Russian version of the Personality Diagnostic Questionnaire - Version 4+ (Hyler, 1994; Dvorshchenko, 2008) and the ICD-10 criteria, save for Narcissistic Disorder diagnosed according to DSMIV criteria, as it is not included in ICD-10.

Early Negative Parental Messages. We adopted Goulding \& Goulding's (1979) definition of injunctions as "messages from the Child ego state of parents, given out of the circumstances of the parent's own pains" (p.34) and assessed 12 injunctions using The Drego Injunction Scale (Drego, 1994). Due to an uncertain validity of the Russian version of the Drego Scale, the psychotherapist used the results of the corresponding assessment as an informative secondary measure whilst basing the diagnosis of the subjects' parental injunctions on the clinical interview and observation.

Statistical analysis.

Study B descriptive statistics: The authors calculated mean scores (M), standard deviations (SD), minimum and maximum scores for social and demographic data such as age, duration of alcohol use, mean age of alcohol dependence onset, etc.

To study relationships between ASD, Personality Types and Injunctions, we analysed correlations using contingency tables as most data was dichotomous. For the same reason, the significance of differences between proportions was tested by means of Fisher's exact test and Pearson's chi-squared method. The null hypothesis was rejected if the differences were significant at the level of $p<0.05$.

Table 1 indicates the personality types for Study B subjects.

\begin{tabular}{lll}
\hline Personality Type & $\begin{array}{l}\text { Number of } \\
\text { People }\end{array}$ & $\begin{array}{l}\% \text { of the } \\
\text { Total }\end{array}$ \\
\hline Borderline & 42 & $22.1 \%$ \\
\hline Antisocial & 32 & $16.8 \%$ \\
\hline Paranoid & 20 & $10.6 \%$ \\
\hline Narcissistic & 15 & $7.9 \%$ \\
\hline Anxious (Avoidant) & 14 & $7.3 \%$ \\
\hline Obsessive-Compulsive & 12 & $6.3 \%$ \\
\hline Schizoid & 11 & $5.8 \%$ \\
\hline Histrionic & 9 & $4.5 \%$ \\
\hline Dependent & 1 & $0.5 \%$ \\
\hline Passive-Aggressive & 1 & $0.5 \%$ \\
\hline Personality Adaptation Trends & 33 & $17.4 \%$ \\
\hline Total & 190 & $\mathbf{1 0 0} \%$ \\
\hline
\end{tabular}

Table 1. Study B Subjects' Personality Types Distribution $(N=190)$

The clients with Personality Adaptation Trends were excluded from Study B analysis as the PA traits were so insignificant that there might have been a high level of bias during their classification on the part of investigators. The clients with Dependent, Passive-Aggressive and Histrionic types were also excluded as the number of observations was insufficient (less than 10) to assess the relationships between studied variables. Clients could be diagnosed with several Personality Adaptations. In this case, a domineering Personality Adaptation alone was used for the following assessment. Thus, 146 clients were assessed in Study B.

\section{Results}

We identified which Parental injunctions the alcoholdependent subjects had and assessed the frequency of their occurrence as illustrated in Table 2.

Table 3 shows correlations ( $r$ ) between Personality Types and Injunctions in the Alcohol-Dependent Clients; Table 4 indicates the major patterns identified, and Table 5 contains correlations between the Personality Types and ASD

We identified three statistically significant positive relationships:

1. Borderline clients' typical injunctions were 'Don't Be Yourself', 'Don't Grow Up', 'Don't Think', 'Don't Be Healthy'. Combined with 'Don't Be' and alcohol dependence, these injunctions displayed mostly as Classical Suicidal Self-Destructiveness.

2. Narcissistic clients had such typical injunctions as 'Don't Be Yourself', 'Don't Be Close', 'Don't Feel', 'Don't Trust'. Combined with 'Don't Be' and alcohol dependence, these injunctions displayed mostly as Alcoholic Professional Self-Destructiveness. 
Note:

Italic Green type and * indicate significant positive correlations ( $r$ is significant at $p<0.05$ ).

Italic Red type and * indicate significant negative correlations ( $r$ is significant at $p<0.05$ ).

$\mathrm{N}-$ number of people with a relevant personality type.

\begin{tabular}{lll|lll}
\hline Injunctions & $\begin{array}{l}\text { Number of } \\
\text { Observations }\end{array}$ & Frequency, \% & Injunctions & $\begin{array}{l}\text { Number of } \\
\text { Observations }\end{array}$ & Frequency, \% \\
\hline Don't Be & 100 & 52.6 & Don't Be Important & 24 & 12.6 \\
\hline Don't Think & 73 & 38.4 & Don't Be Yourself & 22 & 11.6 \\
\hline Don't Be a Child & 54 & 28.4 & Don't Belong & 22 & 11.6 \\
\hline Don't Trust & 53 & 27.9 & Don't Be Close & 20 & 10.5 \\
\hline Don't Feel & 43 & 22.6 & Don't Be Healthy & 15 & 7.9 \\
\hline Don't Grow Up & 39 & 20.5 & Don't & 8 & 4.2 \\
\hline
\end{tabular}

Table 2. Injunctions Identified in Alcohol-Dependent Clients

\begin{tabular}{|c|c|c|c|c|c|c|c|c|c|c|c|}
\hline $\begin{array}{l}\text { Personality } \\
\text { Type }\end{array}$ & 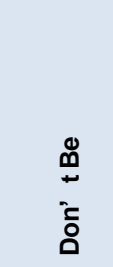 & 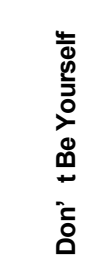 & 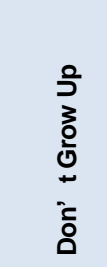 & 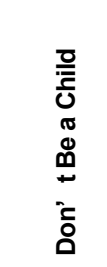 & 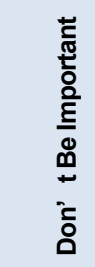 & 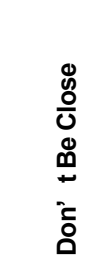 & 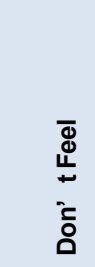 & 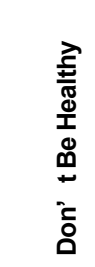 & 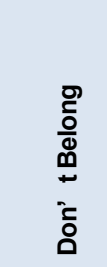 & 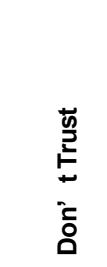 & 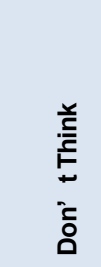 \\
\hline Paranoid $(\mathrm{N}=\mathbf{2 0})$ & $-0.155^{\star}$ & 0.037 & -0.089 & 0.088 & -0.079 & -0.062 & -0.104 & 0.027 & 0.037 & $0.513^{*}$ & $-0.165^{*}$ \\
\hline Schizoid ( $N=11)$ & -0.036 & -0.090 & -0.070 & 0.044 & -0.094 & $0.135^{*}$ & 0.027 & -0.073 & $0.544^{*}$ & -0.104 & $-0.149^{*}$ \\
\hline $\begin{array}{l}\text { Borderline } \\
(\mathrm{N}=42)\end{array}$ & $0.378^{*}$ & $0.204^{*}$ & $0.138^{*}$ & $-0.251^{*}$ & -0.050 & -0.100 & -0.015 & $0.361^{*}$ & $-0.193^{*}$ & -0.077 & $0.361^{*}$ \\
\hline $\begin{array}{l}\text { Antisocial } \\
(\mathrm{N}=32)\end{array}$ & $0.230^{*}$ & $-0.163^{*}$ & $-0.194^{*}$ & -0.034 & 0.083 & -0.017 & $0.160^{*}$ & -0.080 & $-0.163^{*}$ & -0.092 & $0.252^{*}$ \\
\hline $\begin{array}{l}\text { Narcissistic } \\
(\mathrm{N}=15)\end{array}$ & $-0.152^{*}$ & $0.138^{*}$ & 0.045 & -0.098 & 0.065 & $0.154^{*}$ & $0.261^{*}$ & -0.013 & -0.106 & $0.123^{*}$ & -0.031 \\
\hline Anxious ( $\mathrm{N}=14$ ) & $-0.257^{*}$ & 0.024 & $0.256^{*}$ & $-0.133^{*}$ & $0.135^{*}$ & 0.035 & 0.040 & -0.083 & $0.402^{*}$ & -0.041 & $-0.140^{*}$ \\
\hline $\begin{array}{l}\text { Obsessive- } \\
\text { Compulsive } \\
(\mathrm{N}=12)\end{array}$ & -0.057 & -0.094 & $-0.132 *$ & $0.412^{*}$ & -0.099 & 0.052 & -0.089 & -0.076 & -0.094 & -0.017 & $-0.205^{*}$ \\
\hline
\end{tabular}

Table 3. Correlations between Personality Types and Injunctions

\begin{tabular}{ll}
\hline Personality Type & Injunction Patterns \\
\hline Paranoid ( $\mathrm{N}=20)$ & Don't Trust \\
\hline Schizoid ( $\mathrm{N}=11)$ & Don't Be Close, Don't Belong \\
\hline Borderline ( $\mathrm{N}=42)$ & Don't Be, Don't Be Yourself, Don't Grow Up, Don't Be Healthy, Don't Think \\
\hline Antisocial ( $\mathrm{N}=32)$ & Don't Be, Don't Feel, Don't Think \\
\hline Narcissistic ( $=15)$ & Don't Be Yourself, Don't Be Close, Don't Feel, Don't Trust \\
\hline Anxious ( $\mathrm{N}=14)$ & Don't Grow Up, Don't Be Important, Don't Belong \\
\hline Obsessive-Compulsive $(\mathrm{N}=12)$ & Don't Be a Child \\
\hline
\end{tabular}

Table 4. Major Patterns of Injunctions Depending on Personality Types 
Note:

Italic Green type and * indicate significant positive correlations ( $r$ is significant at $p<0.05$ ).

Italic Red type and * indicate significant negative correlations ( $r$ is significant at $p<0.05)$.

$\mathrm{N}$ - number of people with a relevant personality type.

\begin{tabular}{llllllll}
\hline $\begin{array}{l}\text { Personality } \\
\text { Disorder }\end{array}$ & $\begin{array}{l}\text { Borderline } \\
\mathbf{N = 4 2}\end{array}$ & $\begin{array}{l}\text { Antisocial } \\
\mathbf{N = 3 2}\end{array}$ & $\begin{array}{l}\text { Narcissistic } \\
\mathbf{N = 1 5}\end{array}$ & $\begin{array}{l}\text { Schizoid } \\
\mathbf{N = 1 1}\end{array}$ & $\begin{array}{l}\text { Paranoid } \\
\mathbf{N = 2 0}\end{array}$ & $\begin{array}{l}\text { Anxious } \\
\mathbf{N = 1 4}\end{array}$ & $\begin{array}{l}\text { Obsessive- } \\
\text { Compulsive } \\
\mathbf{N = 1 2}\end{array}$ \\
\hline Suicidal (N=40) & $0.223^{*}$ & 0.044 & -0.103 & 0.038 & -0.051 & $-0.146^{*}$ & -0.028 \\
\hline Family (N=68) & 0.079 & 0.016 & -0.015 & -0.044 & 0.102 & 0.126 & -0.104 \\
\hline Somatic (N=40) & -0.057 & -0.060 & -0.103 & 0.073 & 0.075 & 0.101 & 0.025 \\
\hline Risky (N=63) & 0.089 & 0.107 & 0.004 & $-0.173^{*}$ & -0.019 & -0.110 & 0.142 \\
\hline Antisocial (N=53) & 0.008 & $0.347^{*}$ & -0.052 & -0.054 & -0.060 & -0.041 & -0.017 \\
\hline Professional (N=43) & -0.137 & -0.109 & $0.215^{*}$ & 0.027 & 0.019 & 0.040 & 0.015 \\
\hline Note
\end{tabular}

Note that the clients could display signs of different self-destructive behaviours. The analysis took into account all of them, therefore the number of observations in Alcoholic Self-Destructiveness Dimensions exceeds the number of clients classified according to the personality types.

Table 5. Correlations between Personality Types and ASD

3. Antisocial clients' most frequent injunctions were 'Don't Feel', 'Don't Think'. Combined with 'Don't Be' and alcohol dependence, these injunctions displayed mostly as Antisocial Behaviour.

The only two significant negative correlations were identified between the Schizoid personality and the Risky Behaviour Dimension, and the Anxious personality and Classical Suicidal Dimension.

\section{Discussion}

As to the first study objective, we have identified a pattern of injunctions characteristic of the alcohol-dependent clients. These are 'Don't Be', 'Don't Think', 'Don't Be a Child', 'Don't Trust', 'Don't Feel' and 'Don't Grow Up'. It is quite possible that this pattern, especially 'Don't Be' and 'Don't Think', may underlie alcohol dependence. Other injunctions (and their combinations with the foregoing), which we call "mediator" injunctions, may determine alcohol-dependent clients' personality structure and mediate the way the latter injunctions actualise themselves through Alcoholic SelfDestructiveness Dimensions (see Figure 2).

Alternatively, the incidence of 'Don't Be' as measured with the Drego Questionnaire in the alcohol-dependent outpatients was equivalent to our former data obtained purely through clinical observation and interview (Shustov, 2000). It appears that this result reflects the fact that there may be a most self-destructive pool of alcohol-dependent clients. In their case, therapeutic observation and intervention may need to account for the same principles as observation and intervention in oncology (Meehan, 1990).
Self-Destructive Dimensions

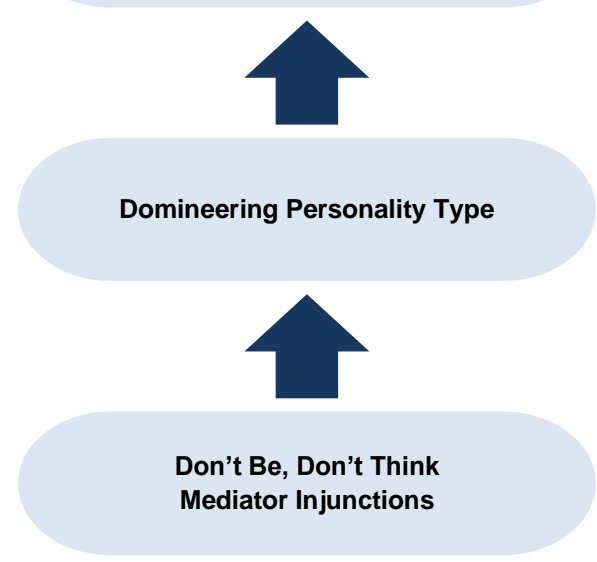

Figure 2. Self-Destructiveness as determined by Personality

Pursuing the second objective has enabled us to single out patterns of injunctions characteristic of the different Personality Types. It is evident that the statistically significant injunctions identified are compatible with the clinical reality of the Personality Types. Thus, the core injunction of the Paranoid clients - 'Don't Trust' - reflects their suspiciousness and jealousy. 'Don't Be Close' is indicative of the Schizoid detachment and withdrawal from contact. Injunctions typical of the Borderline clients are helpful for understanding their challenges related to survival, identity and separation. Injunctions of the Antisocial clients indicate their tendencies to selfdestruction, repression of feelings, and behaving without consideration of consequences. The identified 
injunctions are most apparent in the clinical observation of the Narcissistic, as well as Anxious clients - with their fear of contact ('Don't Belong') and capacity for regression in response to a threatening stimulus ('Don't Grow Up'). The key injunction of the ObsessiveCompulsive clients excludes flexibility, creativity and risk in decision-making.

We identified multiple significant negative correlations between the Personality Types and injunctions. Sometimes they comply quite well with the clinical reality, e.g. 'Don't Grow Up' is found to be untypical of the Obsessive-Compulsive and Antisocial personalities. Alternatively, these findings contradict the clinical reality and need to be conceptualised and investigated further. For instance, we have found that the incidence of 'Don't $\mathrm{Be}$ ' in Paranoid clients is decreased, although there is evidence for jealousy-related suicidal and homicidal behaviour in Paranoid alcohol-dependent clients (Jiménez-Arriero, Hernández, Mearin Manrique, Rodríguez-Jiménez, Jiménez Giménez \& Ponce Alfaro, 2007). As to Narcissistic clients, who display low incidence of 'Don't Be' as well, seemingly they tend to avoid classical suicidal activity as evidenced by the relevant correlations, and engage in a 'less dangerous' professional self-destruction. In any case, investigating other script components - counter-injunctions and program - and their interaction with injunctions, might be helpful to eliminate some contradictions found in the study.

It would also be interesting to measure whether there is quantitative difference (or equivalence) in injunctions in clients with Personality Adaptations and clients with Personality Disorders. In this way we could assess the weight of any environmental or inherited biological factors in the genesis of alcohol dependence, which Davis and Loxton (2013) propose to be a 50:50 ratio. We were unable to assess it within this study, due to an insufficient sample size among other things

We have found a connection between Personality Types and ASD. For instance, Borderline persons actualise their deadly scripts through the Classical Suicidal SelfDestructiveness as confirmed by multiple clinical data on an increased incidence of suicides in Borderline clients, with even more if Borderline Personality Disorder is combined with alcohol dependence, (Preuss, Koller, Barnow, Eikmeier \& Soyka, 2006). As was expected, clients with Antisocial personality actualize their hamartic script through the Antisocial Dimension. Antisocial behaviour and alcohol dependence reinforce each other, and these clients frequently become victims of homicide, police brutality and imprisonment. Narcissistic clients actualize their self-destructive script through not OKness in the area that is most relevant for them, i.e. their profession, as the drive for destruction sustained with alcohol creates a context for losing one's favourite job, exposure to humiliating persecutions and dismissals. Thus, a vicious circle that reinforces drinking and its circumstances, is born.
Unfortunately, other hypothesized connections assumed by us and based on clinical observations (e.g. between the Paranoid personality type and Family SelfDestructiveness; Histrionic personality and Risky behaviour, Schizoid personality and Dual Diagnosis) have not been confirmed statistically.

\section{Limitations of the study}

As has been mentioned in the discussion, one limitation of our study was related to the small sample. It was enough to study the main variables and answer the research question but some questions that appeared during the study have remained unanswered: what relationships could be found if clients with the Dependent, Passive-Aggressive and Histrionic Personality Types had been included in the study; how their inclusion would influence the main pattern of alcoholic mediator injunctions; what is the ratio between environmental and hereditary factors in the origin of alcohol dependence; how different are injunction patterns in alcohol-dependent clients with Personality Adaptations and Personality Disorders, and are they different from the 'normally functioning' alcoholdependent individuals?

Another limitation was the homogeneity of the sample. We excluded women from our study and the sample consisted mostly of highly motivated male clients who applied for the anti-alcohol treatment independently. Thus, this sample may not be representative of the real population of alcohol-dependent clients, lacking especially in-patients, who are often low-motivated, forced to receive treatment by their relatives, employers or other authorities and displaying signs of comorbid disorders (PTSD, major depression, etc).

The last limitation (and, again, a new research perspective), deals with mediators influencing the personality structure and the choice of ASD in alcoholdependent clients. We have studied only one component of the script system, leaving counter-injunctions and program unattended. A detailed empirical study of the script system components and their patterns within a well-organized research using both quantitative and qualitative measures (rather than pure clinical observation) may be needed to fully understand relationships between personality structuring and self-destructive behaviour in alcohol-dependent clients.

\section{Conclusion}

There are a number of injunctions that contribute significantly to the hamartic alcoholic script of the outpatient alcohol-dependent clients on the following continuum from the most to the less frequent: Don't Be, Don't Think, Don't Be a Child, Don't Trust, Don't Feel, Don't Grow Up. Our findings suggest that alcoholdependent clients' personality types are positively associated with unique and specific injunction patterns. We have also found that personality types act as mediators for the corresponding Alcoholic Self- Destruct- 
iveness Dimensions: the Classical Suicidal Dimension is mediated with the Borderline personality traits; Antisocial with the Antisocial personality; and Professional with the Narcissistic Personality.

Dmitri I. Shustov, MD, PhD, TSTA (Psychotherapy), Professor, Chair of the Department of Psychiatry of the Ryazan State Medical University can be contacted on dmitri shustov@mail.ru

Olga D. Tuchina, Psychologist, Lecturer at the Department of Medical and Social Rehabilitation for Substance Use Disorders of the People's Friendship University of Russia, is in training as a Certified Transactional Analyst (Psychotherapy).

Sergei A. Novikov, MD, PhD is in training as a Certified Transactional Analyst (Psychotherapy).

Ilya A. Fedotov, MD, PhD is in training as a Certified Transactional Analyst (Psychotherapy).

\section{References}

Agibalova, Tatiana V., Buzik, Oleg Zh. \& Gurevich, Gennady L. (2011). Znachenie lichnosti bol'nyh alkogolizmom v psihoterapevticheskom processe [Psychotherapy of alcoholics based on personality traits]. Zhurnal nevrologii i psikhiatrii imeni S.S. Korsakova. 11, 39-43. [in Russian]

American Psychiatric Association (1994). Diagnostic and Statistical Manual of Mental Disorders, Fourth Edition. Washington DC: American Psychiatric Association: Author.

Benedetti, Fabrizio. (2013). Placebo and the new physiology of the doctor-patient relationship. Physiological Reviews. 93:3, 1207-1246.

Berne, Eric. (1981). Games people play: The psychology of human relationships. New York, NY: Grove Press.

Chachamovich, Eduardo, Ding, Yang, Turecki, Gustavo. (2012). Levels of aggressiveness are higher among alcoholrelated suicides: results from a psychological autopsy study. Alcohol. 46:6, 529-536.

Constantino, Michael J., Ametrano, Rebecca M. \& Greenberg, Roger P. (2012) Clinician interventions and participant characteristics that foster adaptive patient expectations for psychotherapy and psychotherapeutic change. Psychotherapy. Vol. 49: 4 557-569.

Crossman, Patricia. (1966). Permission and Protection. Transactional Analysis Bulletin. 5:19, 152-154.

Cunningham, John A. \& Breslin, F.Curtis. (2004). Only one in three people with alcohol abuse or dependence ever seek treatment. Addict. Behav. 29, 221-223.

Cunningham, John A. \& McCambridge, Jim. (2012). Is alcohol dependence best viewed as a chronic relapsing disorder? Addiction. 107: 6-12.

Davis, Caroline, Loxton, Natalie J. (2013).Addictive behaviors and addiction-prone personality traits: Associations with a dopamine multilocus genetic profile. Addictive Behaviors. 38:7, 2306-2312.
Drego, Pearl. (1994). Happy family: Parenting through family rituals. Bombay: Alfreruby Publishers.

Dvorshchenko, Valery P. (2008). Diagnosticheskij test lichnostnyh rasstrojstv [Personality Disorders Diagnostic Questionnaire]. Moscow: Rech. [in Russian]

Egorov, A.Y., Krupitsky, Evgeny M., Sofronov A.G., Bobrov A.E., Tyavokina E.Y. \& Dobrovolskaya A.E. (2013). Zloupotrebleniye alkogolem u bol'nykh, ekstrenno gospitalizirovannykh v bol'nitsu skoroy pomoshchi [Alcohol consumption in the patients of somatic hospital]. Obozrenie psikhiatrii I meditsinskoi psikhologii. 1, 36-43. [in Russian].

Goulding, Robert \& Goulding, Mary. (1979) Changing lives through Redecision Therapy. New York: Grove Press.

Hoyt, Michael F. (1989) Psychodiagnosis of personality disorders. Transactional Analysis Journal. 19:2, 101-113.

Hyler, Steven E. (1994). PDQ-4+ Personality Diagnostic Questionnaire-4+. New York, NY: New York State Psychiatric Institute.

Jiménez-Arriero, Miguel Ángel, Hernández, Belén, Mearin Manrique, Ignacio; Rodríguez-Jiménez, Roberto; Jiménez Giménez, Mónica; Ponce Alfaro, Guillermo. (2007). Celopatía alcohólica: un antiguo y actual dilema [Alcoholic jealousy: an old and current dilemma]. Adicciones. 19:3, 267-272. [in Spanish]

Joines, Vann. (1986). Using redecision therapy with different personality adaptations. Transactional Analysis Journal. 16:3, $152-160$.

Joines, Vann. (1988) Diagnosis and Treatment planning using a transactional analysis framework. Transactional Analysis Journal. 18:3, 185-190

Joines, Vann \& Stewart, lan. (2002). Personality adaptations: A new guide to human understanding in psychotherapy and counseling. Nottingham and Chapel Hill: Lifespace Publ.

Kocic, Sanja, Radovanovic, Snezana, Vasiljevic, Dragan, Milosavljevic, Mirjana, Djordjevic, Gordana \& Zivanovic, Sandra. (2012). Sex as suicidal risk factor. MED PREGLED, 65:9-10, 415-420.

Larkin, Celine, Di Blasi, Zelda \& Arensman, Ella. (2014). Risk Factors for Repetition of Self-Harm: A Systematic Review of Prospective Hospital-Based Studies. PLoS ONE. 9:1, e84282. http://www.ncbi.nlm.nih.gov/pmc/articles/PMC3896350/pdf/pone.0084 282.pdf accessed December, 2015.

Leonhard, Karl. (1968). Accentuated Personalities [Akzentuierte Persönlichkeiten]. Verl. Volk u. Gesundheit VEB.

Lichko, Andrey E. (1983) Psikhopatii i aktsentuatsii kharaktera u podrostkov [Psychopathy and accentuations of character at teenagers]. Leningrad: Meditsina. [in Russian]

Magill, Molly \& Ray, Lara A. (2009). Cognitive-behavioural treatment with adult alcohol and illicit drug users: a metaanalysis of randomized controlled trials. J Stud Alcohol Drugs. 70, 516-527.

McNeel, John. (1976). The Parent interview. Transactional Analysis Journal. 6:1, 61-68 
Meehan, Patrick J. (1990). Prevention: the endpoint of suicidology. Mayo Clinic proceedings. 65:1, 115-118.

Menninger, Karl Augustus. (1938). Man against himself. New York, NY: Harcourt, Brace.

Merinov, Alexei V. \& Shustov, Dmitri I. (2012). Phenomen final'noj otkrytosti semejnoi sistemi v brakakh stradayushchikh alkogol'noj zavisimost'ju muzhchin [Phenomenon of the open final in the family systems of married men suffering from alcohol dependence]. Zh Nevrol Psikhiatr Im S S Korsakova. 112:10, 64-67. [in Russian]

Mishra, Biswa R., Nizamie, S. Haque, Das, Basudeb \& Praharaj, Samir K. (2010). Efficacy of repetitive transcranial magnetic stimulation in alcohol dependence: a sham-controlled study. Addiction. 105:1, 49-55.

Najavits, Lisa M. (2013). Creating change: a new past-focused model for PTSD and substance abuse. In P. Ouimette \& J. P.

Read (Eds.), Handbook of Trauma, PTSD and Substance Use Disorder Comorbidity. Washington, DC: American

Psychological Association Press.

National Institute on Alcohol Abuse and Alcoholism. (2006).

National epidemiologic survey on alcohol and related conditions. Alcohol Alert. 70.

http://pubs.niaaa.nih.gov/publications/AA70/AA70.pdf accessed September 2015.

National Institute on Drug Abuse. (2012). Principles of drug addiction treatment: a research-based guide. NIH Publication No. $12-4180$.

Niciu, Mark J. \& Arias, Albert J. (2013). Targeted opioid receptor antagonists in the treatment of alcohol use disorders. CNS Drugs. 27:10, 777-787.

Novikov, Sergey A. (2014). Alkogol'naja zavisimost' i projavlenija autoagressivnogo povedenija u pacientov $s$ razlichnymi tipami lichnosti [Alcohol dependence and selfdestructiveness manifestations in patients with different personality types]. Candidate of Medical Science Thesis; Addiction Medicine. Moscow, National Research Centre for Addictions of the Ministry of Healthcare / Ryazan, Ryazan State Medical University.

O'Farrell TJ, \& Clements K. (2012) Review of outcome research on marital and family therapy in treatment for alcoholism. J Marital Fam Ther. 38(1),122-44.

Osnes, Russel E. (1974). Spot Reparenting. Transactional Analysis Journal. 4:3, 40-46.

Pompili, Maurizio, Serafini, Gianluca, Innamorati, Marco, Dominici, Giovanni, Ferracuti, Stefano, Kotzalidis, Giorgio D. Serra, Giulia, Girardi, Paolo, Janiri, Luigi, Tatarelli, Roberto, Sher, Leo \& Lester, David. (2011). Suicidal Behaviour and Alcohol Abuse. Int J Environ Res Public Health. 7:4, 13921431.

Preuss, Ulrich W., Koller, Gabriele, Barnow, Sven, Eikmeier, Markus, Soyka, Michael. (2006). Suicidal behavior in alcoholdependent subjects: the role of personality disorders. Alcohol Clin Exp Res. 30:5, 866-877.
Shustov, Dmitri I. (2000). Autoagressivnoe povedenie i alkogolizm (Kliniko-terapevticheskoe issledovanie) [Selfdestructive behaviour and alcoholism: clinical and therapeutic study]: Doctor of Medical Science Thesis; Psychiatry, Addiction Medicine. Ryazan, Ryazan State Medical University. [in Russian]

Shustov, Dmitri I. (2005). Autoagressija, suicid i alkogolizm [Self-destructiveness, Suicide and Alcoholism]. Moscow: Cogito-Center. [in Russian]

Shustov, Dmitri I. (2009). Rukovodstvo po klinicheskomu transaktnomu analizu [Handbook on Clinical Transactional Analysis]. Moscow: Cogito-Center. [in Russian]

Shustov, Dmitri I., Ivannikov, Yuri A. \& Merinov, Alexei V. (1999). Ob otnoshenii bol'nykh alcogolismom $k$ faktoru ognia [On the attitude of patients with alcoholism to the factor of fire] Pavlovskiye idei $v$ razvitii sovremennoy nauki. Book of abstracts. Ryazan: Ryazan State Medical University, 101-103. [in Russian].

Shustov, Dmitri I., Merinov, Alexei V. \& Tuchina, Olga. (2015). Episcript transmission in families of alcohol-dependent men: models and clinical observations. Transactional Analysis Journal. Published online before print.

http://tax.sagepub.com/content

learly/2015/10/27/0362153715615120 accessed November, 2015.

Shustov, Dmitri I., Merinov, Alexei V. \& Valentik, Yuri V. (2000). Diagnostika autoagressivnogo povedenija pri alkogolizme metodom terapevticheskogo interv'ju [Diagnosing self-destructiveness in patients with alcohol dependence using therapeutic interview]. Moscow: Ministry of Healthcare of the Russian Federation. [in Russian].

Steiner, Claude. (1974). Games alcoholics play: The analysis of life scripts. New York, NY: Ballantine Books.

Tilney, Tony. (1998). Dictionary of Transactional Analysis. London, Whurr Publishers Ltd.

Ware, Paul. (1983). Personality adaptations (doors to therapy) Transactional Analysis Journal. 13:1, 11-19.

Wedig, Michelle M., Silverman, Merav H., Frankenburg, Frances R., Reich, D. Bradford, Fitzmaurice, Garrett \& Zanarini, Mary C. (2012). Predictors of suicide attempts in patients with borderline personality disorder over 16 years of prospective follow-up. Psychol Med. 42:11, 2395-2404.

World Health Organization. (1992). The ICD-10 classification of mental and behavioural disorders: Clinical descriptions and diagnostic guidelines. Geneva, Switzerland: Author 